\title{
ANALISA PERBANDINGAN WAKTU DAN KECEPATAN TRANSFER PADA MULTI PROTOCOL LABEL SWITCHING (MPLS) DENGAN VIRTUAL PRIVATE NETWORK (VPN) UNTUK PERPINDAHAN DOKUMEN PADA JARINGAN KOMPUTER
}

\author{
Ibrahim Saleh, Hero Wintolo, Dwi Nugraheny \\ Jurusan Teknik Informatika \\ Sekolah Tinggi Teknologi Adisutjipto \\ informatika@stta.ac.id
}

\begin{abstract}
MPLS (Multi Protocol Label Switching) technology has been developed and mostly used by the service provider on their main network. Data packets which forwarded from one router to another router can also use VPN (Virtual Private Network) technology. VPNs were developed in the field of computer networks now have many variants, such as MPLS VPN and VPN which connects between computers or a LAN through a public network is the internet. The purpose of this final task is build a lab scale VPN network with MPLS technology use Mikrotik router RB $750 G L$ and create a VPN connection to the STTA campus network passing the public internet. Then do a comparative analysis of the time required and the speed of transfer on both the network. The results of a comparative analysis between MPLS and VPN with the same file capacity, it appears that the MPLS network is faster in time speed and transfer speed.
\end{abstract}

Keyword: Comparative Analysis, MPLS, VPN.

\section{Pendahuluan}

Seiring berjalannya waktu, manusia membutuhkan sebuah solusi untuk mempermudah dalam hal memperoleh kecepatan waktu, meringankan biaya pengeluaran, serta mendapat kemudahan berkomunikasi tanpa memikirkan tempat yang jauh. Hal ini dapat diperoleh dengan membangun jaringan MPLS.Teknologi MPLS (Multi Protocol Label Switching) telah berkembang dan banyak digunakan oleh para ISP (Internet Service Provider) pada jaringan utama mereka. Dengan kelebihannya dalam meneruskan paket berdasarkan label lookup dan bukan lagi berdasarkan IP lookup, membuatnya lebih cepat dan core router tidak perlu mengetahui tentang rute pelanggan, sehingga tidak perlu menjalankan perutingan BGP (Border Gateway Protocol).

MPLS terdiri dari dua komponen utama, yaitu control plane untuk mempertukarkan informasi routing layer 3, label dan forwarding plane untuk meneruskan paket berdasarkan alamat tujuan maupun label.Paket data yang diteruskan dari satu router ke router yang lainnya dapat juga menggunakan teknologi VPN (Virtual Private Network). VPN yang dikembangkan dalam bidang ilmu jaringan komputer sekarang memiliki varian yang banyak, antara lain VPN MPLS dan VPN yang menghubungkan antar komputer atau LAN melewati jaringan publik yaitu internet. 


\section{Metodologi}

\subsection{Tinjauan Pustaka}

Teknologi MPLS (Multi Protocol Label Switching) untuk Meningkatkan Performa Jaringan. Dalam perancangan dan pembuatan sistem ini terdapat penelitian terdahulu yaitu karya Iwan Rijayana yang membahas tentang bagaimana cara kerja MPLS dan analisa paket-paket data ketika mengirimkan paket dalam jaringannya. Konsep ini cukup membantu dalam membangun sebuah sistem untuk menerapkan jaringan MPLS pada tugas akhir ini.

\subsection{Pengertian Jaringan Komputer}

Jaringan komputer adalah hubungan interkoneksi antara dua komputer autonomous atau lebih yang terhubung dengan media transmisi kabel atau tanpa kabel (wireless). Bila sebuah komputer dapat membuat komputer lainnya restart, shutdown, atau melakukan kontrol lainnya, maka komputer-komputer tersebut bukan bukan autonomous (tidak melakukan kontrol terhadap komputer lain dengan akses penuh). (Tanenbaum. A S, 2000)

\subsection{Teknologi Jaringan Komputer}

\subsubsection{MPLS}

MPLS inti meliputi (LSRs) Label Switching Router Label. Masing-masing LSR akan saling terkait membentuk rangkaian jaringan MPLS yang di hubungkan oleh (LSP) Label Switched Path. Setiap LSP akan diidentifikasi pemasangan label oleh (FEC) Forwarding Equivalence Class. Header MPLS terdiri atas 32 bit data, termasuk 20 bit label, 2 bit eksperimen, dan 1 bit identifikasi stack, serta 8 bit TTL. MPLS memiliki kecepatan menggabungkan beberapa kelebihan dari sistem komunikasi circuit-switched dan packet switched. (Bongale. A M, 2012)

\subsubsection{VPN}

Jaringan VPN (Virtual Private Network) adalah jaringan komputer dimana dapat digunakan untuk menggabungkan antar jaringan individu di lokasi yang berbeda dalam satu jaringan yang dipisahkan dengan jarak yang jauh. Dengan kata lain, contoh bahwa pengguna kebetulan berjarak 15.000 kilometer dari datanya. Akan tetapi seolah-olah mereka berada di dalam jaringan lokal. (Tanenbaum. A S, 2011)

\subsection{Analisa Kebutuhan Perangkat Keras dan Perangkat Lunak}

Pembuatan sebuah tugas akhir tentang jaringan komputer, terlebih dahulu disusun berdasarkan kebutuhan peralatan dalam bentuk perangkat keras, perangkat lunak dan jaringan komputer.

\subsubsection{Analisa Kebutuhan Perangkat Keras}

1. Komputer desktop.
a. Processor : Intel ${ }^{\circledR}$ Core $^{\mathrm{TM}} i 7-2600 \mathrm{~K}$ Processor $3.40 \mathrm{GHz}$ (8M Cache, up to $3.80 \mathrm{GHz})$
b. Motherboard : Gigabyte H67MA USB3 B3 sudah mendukung Gigabit LAN port.
c. RAM : $8 \mathrm{~GB}$ 
d. Hardisk :2 TB

e. Wireless LAN USB adapter.

2. Laptop
a. Processor : Intel ${ }^{\mathbb{B}}$ Atom $^{\mathrm{TM}}$ processor $\mathrm{N} 280$
b. RAM : 1 GB
c. Hardisk : $160 \mathrm{~GB}$
d. LAN port dan Wireless LAN sudah terpasang di dalamnya.

\subsubsection{Analisa Kebutuhan Perangkat Lunak}

1. Sistem Operasi : Microsoft Windows 7 Ultimate 64 bit.

2. Sistem Operasi : Microsoft Windows 8 Pro with Media Center 32bit.

3. Borland Delphi 7

4. Microsoft Office 2010

5. Microsoft Visio 2010

6. Cisco Packet Tracer

\subsubsection{Analisa Kebutuhan Alat-alat Jaringan Komputer}

Sebuah jaringan komputer terdiri atas alat-alat jaringan komputer. Di bawah ini adalah alat-alat yang diperlukan dalam membuat jaringan komputer terutama pada jaringan VPN dan MPLS.

1. Tiga buah Router MikroTik RouterBOARD 750 GL.

2. Kabel UTP kategori 6e

3. Modem ADSL (Asymmetric Digital Subscriber Line)

4. Modem GSM NOVATEL WIRELESS Ovation MC990D

\subsection{Perancangan Jaringan MPLS}

Perancangan jaringan komputer MPLS ini menggunakan 3 buah router. 1 router dijadikan routerprovider dan 2 router dijadikan provider edge (sisi tepi dari provider). Pada sisi client, dibutuhkan 1 router dari tiap-tiap jaringan untuk dapat terhubung dengan jaringan MPLS. Gambar 1 adalah gambaran perancangan dari jaringan MPLS. 


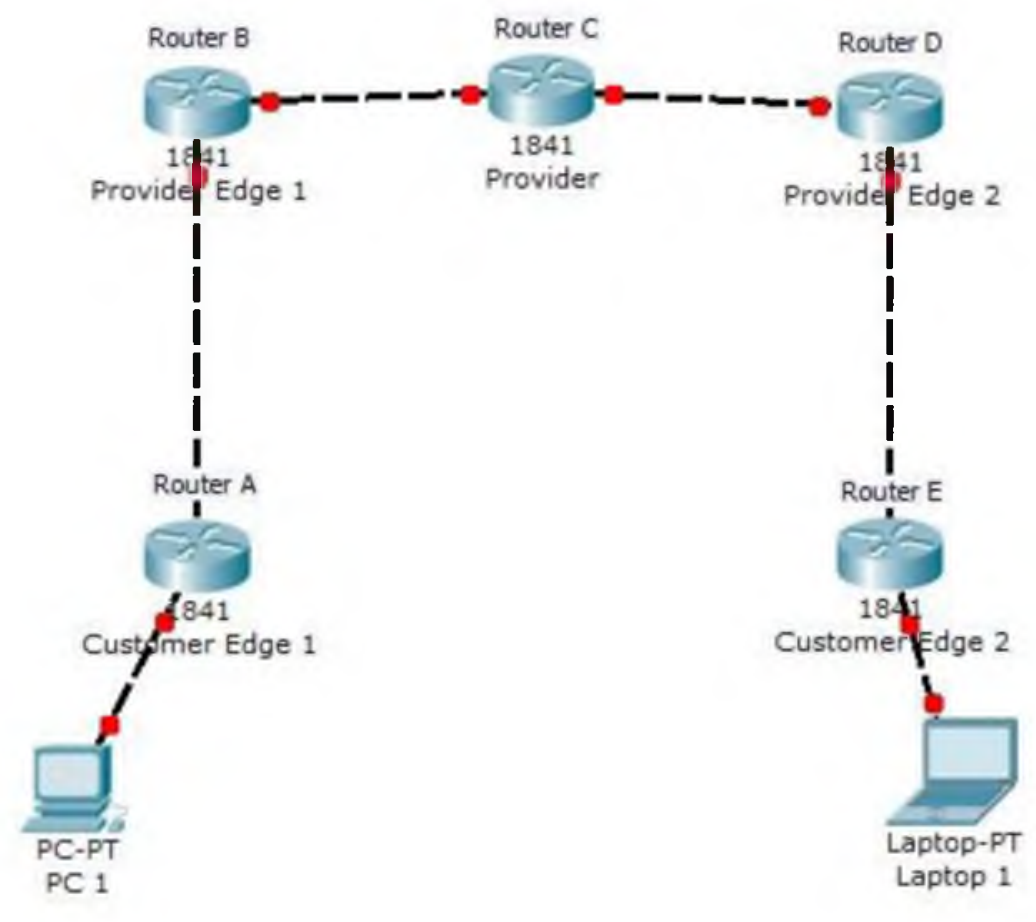

Gambar 1. Gambaran perancangan jaringan MPLS

\subsection{Perancangan Jaringan VPN}

Perancangan yang kedua adalah jaringan VPN yang melewati publik internet seperti pada gambar 2. Perancangan jaringan VPN ini merupakan penerapan jaringan VPN yang sudah sering dipakai oleh pengguna secara umum.

Fitur jaringan VPN ini sudah tersedia di dalam sistem operasi Windows. Fungsi dari jaringan VPN ini adalah pengguna dapat terhubung langsung ke jaringan tujuan dengan istilah melewati tunnel (terowongan) di internet. Alat perantara untuk menghubungkan jaringan VPN dapat dengan menggunakan modem GSM, modem ADSL, dan Wi-Fi. Hal yang penting yaitu dapat terhubung ke internet.

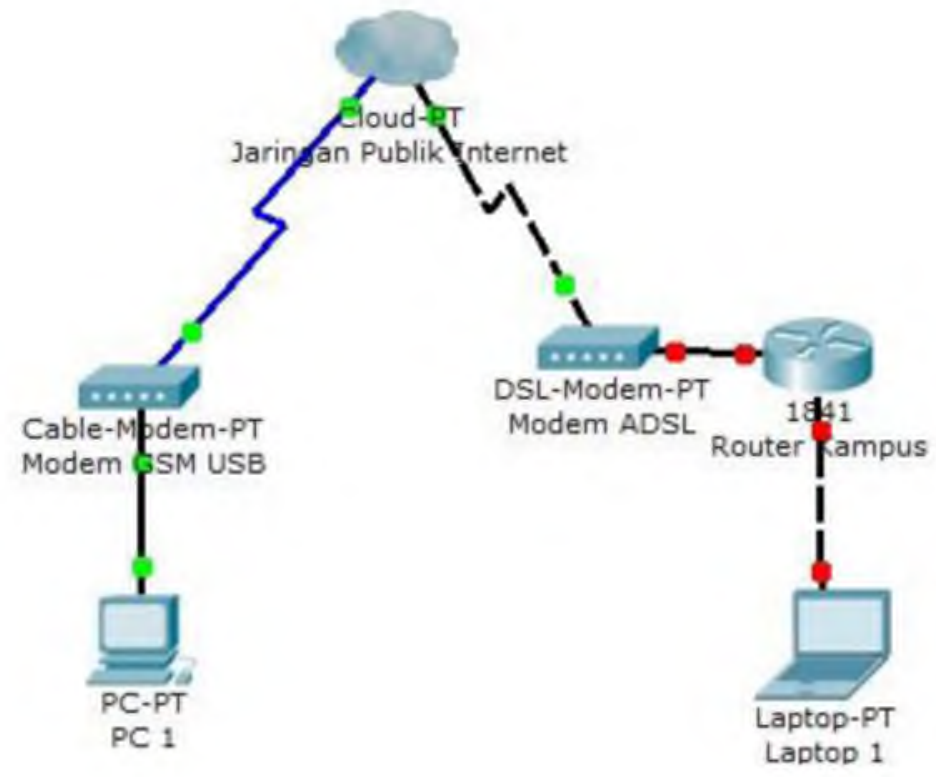

Gambar 2. Gambaran perancangan jaringan VPN 


\subsection{Konfigurasi Jaringan}

\subsubsection{Konfigurasi Jaringan MPLS}

Gambar 3 adalah perancangan pengalamatan IP pada tiap-tiap router dari jaringan MPLS.Teknologi yang digunakan yaitu:

- LDP untuk MPLS label distribusi

- BGP untuk VPNv4 routing distribusi

- OSPF sebagai protokol perutingan Consumer Edge ke Provider Edge.

Software yang dibutuhkan yaitu:

- Router provider dan provider edge harus mempunyai RouterOS 3.17 dengan routing-test dan mpls-test paket.

- Routercostumer edge harus mempunyai RouterOS 3.17 dengan routing-test paket. (routing-test paket dan versi yang lebih lama dapat digunakan sama baiknya)

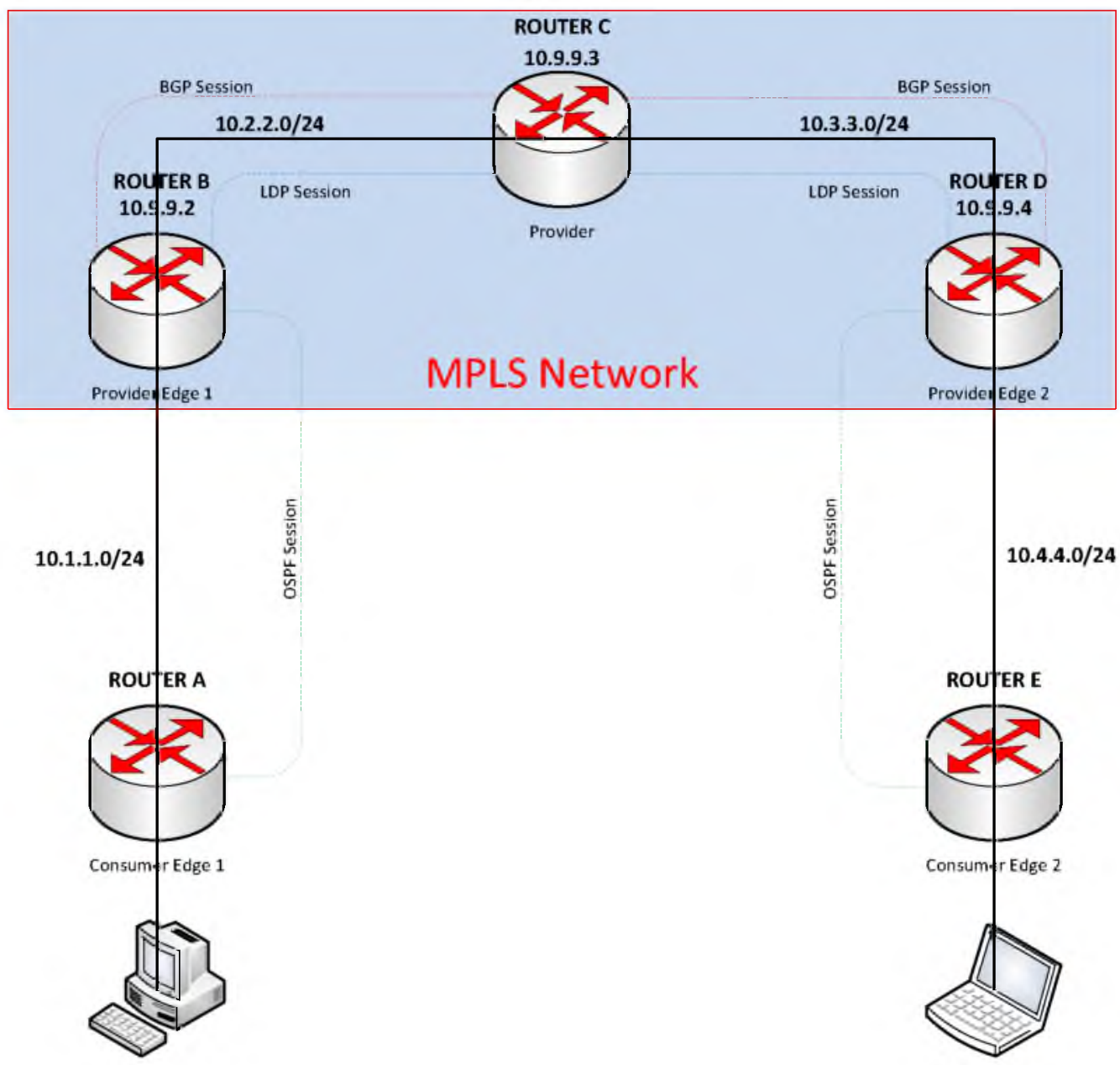

Gambar 3. Perancangan pengalamatan IP dan pe-routing-an pada jaringan MPLS

\subsubsection{Konfigurasi Jaringan VPN}

Setelah mengetahui konfigurasi untuk jaringan MPLS, langkah selanjutnya adalah mengkonfigurasi jaringan VPN yang menghubungkan dari modem GSM atau modem ADSL menuju ke jaringan kampus STTA (Sekolah Tinggi 
Teknologi Adisutjipto). Langkah-langkah mengkonfigurasi jaringan VPN adalah mengkonfigurasi dan menghubungkan modem GSM, kemudian membuat koneksi VPN di sistem operasi Windows.

\subsection{PerancanganUser Interface Program}

Pembahasan ini menjelaskan perencanaan program Adisutjipto Transfer Files (ATF). Pembuatan perancangan User Interface program ini menggunakan program Microsoft Visio 2010. Untuk perencanaan user interface program, Program ATF terdiri dari enam form yaitu :

1. Form Utama (Adisutjipto Transfer Files)

2. Form Cek IP dan Hostname

3. Form Petunjuk Penggunaan

4. Form Tentang Program

5. Form Pembuat Program

6. FormEmail

\section{Hasil dan Pembahasan}

\subsection{Pengujian Jaringan dengan Program ATF (Adisutjipto Transfer Files)}

Pada saat pengujian program ATF pada jaringan MPLS dan VPN, dilakukan pencatatan waktu yang dibutuhkan untuk mengirim file dari laptop ke komputer desktop. Pengujian perbandingan menggunakan 10 file dengan kapasitas yang berbeda-beda. Setiap file ditetapkan bahwa besar file meningkat dua kali lipat dengan besar awal file sebesar 1 MB sampai dengan 512 MB.Tabel 1 merupakan hasil pengujian jaringan antara dua jaringan yaitu jaringan MPLS dengan jaringan VPN dengan program ATF.

Tabel 1. Hasil Pengujian pada Jaringan MPLS dan Jaringan VPN

\begin{tabular}{|l|l|l|}
\hline \multirow{2}{*}{$\begin{array}{c}\text { Kapasitas } \\
\text { File }\end{array}$} & \multicolumn{2}{|c|}{ Waktu Yang Dibutuhkan (Detik) } \\
\cline { 2 - 3 } & MPLS & VPN \\
\hline $1 \mathrm{MB}$ & 4,81 & 110,51 \\
\hline $2 \mathrm{MB}$ & 5,09 & 219,79 \\
\hline $4 \mathrm{MB}$ & 5,10 & 300,74 \\
\hline $8 \mathrm{MB}$ & 5,72 & 326,32 \\
\hline $16 \mathrm{MB}$ & 6,36 & $1.023,93$ \\
\hline $32 \mathrm{MB}$ & 7,57 & $4.526,43$ \\
\hline $64 \mathrm{MB}$ & 10,40 & $9.245,19$ \\
\hline $128 \mathrm{MB}$ & 16,17 & GAGAL \\
\hline $256 \mathrm{MB}$ & 27,57 & GAGAL \\
\hline $512 \mathrm{MB}$ & 50,31 & GAGAL \\
\hline
\end{tabular}

Penjelasan baris ke satu pada tabel 1 bahwa program ATF mengirim file dari laptop ke komputer desktop dengan kapasitas 1 MB di jaringan MPLS membutuhkan waktu 4,81 detik. Sedangkan program ATF mengirim file dengan kapasitas file yang sama di jaringan VPN membutuhkan waktu 110.51 detik. Penetapan hasil pengujian dikatakan gagal ketika program sedang berjalan dengan normal tetapi pada progress 
bar tidak bergeser ke arah kanan dalam waktu lebih dari 12.600 detik (3,5 jam) selama dua kali percobaan.

\subsection{Perhitungan Kecepatan Transfer}

Data-data yang diperoleh setelah melakukan pengujian, selanjutnya diolah untuk perhitungan kecepatan transfer. Perhitungan pada pembahasan ini berupa mencari berapa kecepatan transfer yang sebenarnya pada masing-masing jaringan yang dibuat. Rumus kecepatan transfer adalah :

$\mathrm{V}=\frac{\text { besar kapasitas file (bit) }}{\text { waktu }(s)}$

Rumus (1)

Tabel 2 adalah hasil dari perhitungan kecepatan transfer pada jaringan MPLS dan tabel 3 adalah hasil perhitungan kecepatan transfer pada jaringan VPN.

Tabel 2. Hasil Perhitungan Kecepatan Transfer pada Jaringan MPLS

\begin{tabular}{|c|c|c|c|c|c|c|}
\hline \multirow{2}{*}{ No } & \multirow{2}{*}{\multicolumn{2}{|c|}{ KapasitasFile (Bits) }} & \multirow{2}{*}{$\begin{array}{c}\text { Waktu Yang } \\
\text { Dibutuh } \\
\text { kan } \\
\text { (Detik) }\end{array}$} & \multicolumn{3}{|c|}{$\begin{array}{l}\text { Kecepatan Transfer } \\
\text { (KapasitasFile / Waktu) }\end{array}$} \\
\hline & & & & bps & Kbps & $\begin{array}{r}\text { Mbp } \\
\text { s }\end{array}$ \\
\hline 1 & 8.388 .608 & bits & 4,81 & $1.743 .993,35$ & $1.743,99$ & 1,74 \\
\hline 2 & 16.777 .216 & bits & 5,09 & $3.296 .113,16$ & $3.296,11$ & 3,30 \\
\hline 3 & 33.554 .432 & bits & 5,10 & $6.579 .300,39$ & $6.579,30$ & 6,58 \\
\hline 4 & 67.108 .864 & bits & 5,72 & $11.732 .318,88$ & $11.732,32$ & 11,73 \\
\hline 5 & 134.217.728 & bits & 6,36 & $21.103 .416,35$ & $21.103,42$ & 21,10 \\
\hline 6 & 268.435 .456 & bits & 7,57 & $35.460 .430,12$ & $35.460,43$ & 35,46 \\
\hline 7 & 536.870 .912 & bits & 10,40 & $51.622 .203,08$ & $51.622,20$ & 51,62 \\
\hline 8 & 1.073 .741 .824 & bits & 16,17 & $66.403 .328,63$ & $66.403,33$ & 66,40 \\
\hline 9 & 2.147 .483 .648 & bits & 27,57 & $77.892 .043,82$ & $77.892,04$ & 77,89 \\
\hline 10 & 4.294 .967 .296 & bits & 50,31 & $85.370 .051,60$ & $85.370,05$ & 85,37 \\
\hline \multicolumn{4}{|c|}{ RATA-RATA } & $36.120 .319,94$ & $36.120,32$ & 36,12 \\
\hline
\end{tabular}

Tabel 3. Hasil Perhitungan Kecepatan Transfer pada Jaringan VPN

\begin{tabular}{|c|c|c|c|c|c|c|}
\hline \multirow[t]{2}{*}{ No } & \multirow{2}{*}{\multicolumn{2}{|c|}{ Kapasitas File (Bits) }} & \multirow{2}{*}{$\begin{array}{c}\text { Waktu Yang } \\
\text { Dibutuhkan } \\
\text { (Detik) }\end{array}$} & \multicolumn{3}{|c|}{$\begin{array}{c}\text { Kecepatan Transfer (Kapasitas } \\
\text { File / Waktu) }\end{array}$} \\
\hline & & & & bps & Kbps & Mbps \\
\hline 1 & 8.388 .608 & bits & 110,51 & $75.908,14$ & 75,91 & 0,08 \\
\hline 2 & 16.777 .216 & bits & 219,79 & $76.332,94$ & 76,33 & 0,08 \\
\hline 3 & 33.554 .432 & bits & 300,74 & $111.572,89$ & 111,57 & 0,11 \\
\hline 4 & 67.108 .864 & bits & 326,32 & $205.653,54$ & 205,65 & 0,21 \\
\hline 5 & 134.217 .728 & bits & $1.023,93$ & $131.080,96$ & 131,08 & 0,13 \\
\hline 6 & 268.435 .456 & bits & $4.526,43$ & $59.304,01$ & 59,30 & 0,06 \\
\hline 7 & 536.870 .912 & bits & $9.245,19$ & $58.070,30$ & 58,07 & 0,06 \\
\hline 8 & 1.073 .741 .824 & bits & GAGAL & 0,00 & 0,00 & 0,00 \\
\hline
\end{tabular}




\begin{tabular}{|l|ll|l|l|l|l|}
\cline { 2 - 7 } 9 & 2.147 .483 .648 & bits & GAGAL & 0,00 & 0,00 & 0,00 \\
\hline 10 & 4.294 .967 .296 & bits & GAGAL & 0,00 & 0,00 & 0,00 \\
\hline \multicolumn{2}{|l|}{ RATA-RATA } & $102.560,40$ & 102,56 & 0,10 \\
\hline
\end{tabular}

Penjelasan tabel 2 pada baris ke satu adalah dengan kapasitas file sebesar 8.388.608 bits pada jaringan MPLS memperoleh kecepatan transfer 1.743.993,35 bps, jika dijadikan dalam satuan kilobits per second (Kbps), maka memperoleh kecepatan $1.743,99 \mathrm{Kbps}$, dan pada satuan megabits per second (Mbps) memperoleh kecepatan 1,74 Mbps. Penjelasan tersebut sama dengan penjelasan pada baris dua dan seterusnya. Hal tersebut sama dengan tabel 3 pada jaringan VPN. Sedangkan pada perhitungan kecepatan rata-rata, hasil kecepatan pada masing-masing kolom dijumlahkan per kolom lalu dibagi dengan jumlah data yang ada. Kecuali pada tabel 3 dimana pengujian yang gagal (hasil sama dengan 0) maka tidak masuk perhitungan rata-rata.

\subsection{Analisa Perbandingan}

\subsubsection{Analisa Perbandingan Waktu yang Dibutuhkan}

Proses analisa perbandingan waktu yang dibutuhkan yaitu dengan mengurangi waktu yang dibutuhkan pada hasil pengujian waktu yang lebih lama dengan hasil pengujian waktu yang lebih cepat. Dalam hal ini waktu yang dibutuhkan pada jaringan VPN dikurangi dengan waktu yang dibutuhkan pada jaringan MPLS. Selisih waktu tersebut ditulis pada tabel analisa dengan kolom selisih waktu. Pada kolom hasil analisa perbandingan dicatat selisih waktu antara waktu yang dibutuhkan. Hasil dari analisa perbandingan ini kemudian ditentukan mana yang lebih cepat dan dicatat hasil dari analisa tersebut. Pada Tabel 4 merupakan hasil dari analisa perbandingan kedua jaringan antara MPLS dan VPN.

Tabel 4. Hasil Analisa Perbandingan antara MPLS dengan VPN berdasarkan kapasitas file dan waktu yang dibutuhkan

\begin{tabular}{|l|l|l|l|lll|}
\hline \multirow{2}{*}{ KapasitasFile } & $\begin{array}{c}\text { Waktu } \\
\text { Dibutuhkan } \\
\text { (Detik) }\end{array}$ & $\begin{array}{c}\text { Yang } \\
\text { SelisihWaktu } \\
\text { (Detik) }\end{array}$ & HasilAnalisaPerbandingan & \\
\cline { 2 - 3 } & MPLS & VPN & & & & \\
\hline $1 \mathrm{MB}$ & 4,81 & 110,51 & 105,70 & LEBIH CEPAT MPLS & 105,70 & DETIK \\
\hline $2 \mathrm{MB}$ & 5,09 & 219,79 & 214,70 & LEBIH CEPAT MPLS & 214,70 & DETIK \\
\hline $4 \mathrm{MB}$ & 5,10 & 300,74 & 295,64 & LEBIH CEPAT MPLS & 295,64 & DETIK \\
\hline $8 \mathrm{MB}$ & 5,72 & 326,32 & 320,60 & LEBIH CEPAT MPLS & 320,60 & DETIK \\
\hline $16 \mathrm{MB}$ & 6,36 & $1.023,93$ & $1.017,57$ & LEBIH CEPAT MPLS & $1.017,57$ & DETIK \\
\hline $32 \mathrm{MB}$ & 7,57 & $4.526,43$ & $4.518,86$ & LEBIH CEPAT MPLS & $4.518,86$ & DETIK \\
\hline $64 \mathrm{MB}$ & 10,40 & $9.245,19$ & $9.234,79$ & LEBIH CEPAT MPLS & $9.234,79$ & DETIK \\
\hline $128 \mathrm{MB}$ & 16,17 & GAGAL & - & & MPLS DAPAT MENGIRIM FILE & \\
\hline $256 \mathrm{MB}$ & 27,57 & GAGAL & - & MPLS DAPAT MENGIRIM FILE & \\
\hline $512 \mathrm{MB}$ & 50,31 & GAGAL & - & & MPLS DAPAT MENGIRIM FILE & \\
\hline RATA - RATA & 13,91 & $2.250,42$ & $2.243,98$ & & & \\
\hline
\end{tabular}


Penjelasan tabel 4 pada kolom hasil analisa perbandingan baris Ke Satu Bahwa Jaringan MPLS Membutuhkan Waktu Lebih Cepat 105,70 Detik Daripada Jaringan VPN. Hal Ini Diperoleh Dari Hasil Waktu Yang Dibutuhkan Pada Jaringan VPN Dikurangi Dengan Hasil Waktu Yang Dibutuhkan Pada Jaringan MPLS. Yakni 110,51 Detik Dikurangi 4,81 Detik Sama Dengan 105,70 Detik. Pada Baris 8 Sampai 10 Penentuan Hasil Analisa Berdasarkan Keberhasilan Jaringan Dalam Pengujian Pengiriman File Dengan Program ATF.

\subsubsection{Analisa Perbandingan Kecepatan Transfer}

Perbandingan dilakukan pada perhitungan kecepatan transfer antara jaringan MPLS dengan jaringan VPN. Dengan demikian, akan diperoleh hasil analisa kecepatan kedua jaringan tersebut. Tabel 5 adalah hasil analisa perbandingan kecepatan transfer.

Tabel 5. Hasil Analisa Perbandingan Kecepatan Transfer

\begin{tabular}{|l|l|l|l|}
\hline \multirow{2}{*}{ KapasitasFile } & \multicolumn{2}{|c|}{$\begin{array}{c}\text { Kecepatan } \\
\text { Transfer } \\
\text { (Mbps) }\end{array}$} & \multirow{2}{*}{ HasilAnalisaPerbandingan } \\
\cline { 2 - 3 } & MPLS & VPN & \\
\hline $1 \mathrm{MB}$ & 1,74 & 0,08 & LEBIH CEPAT MPLS DARIPADA VPN \\
\hline $2 \mathrm{MB}$ & 3,30 & 0,08 & LEBIH CEPAT MPLS DARIPADA VPN \\
\hline $4 \mathrm{MB}$ & 6,58 & 0,11 & LEBIH CEPAT MPLS DARIPADA VPN \\
\hline $8 \mathrm{MB}$ & 11,73 & 0,21 & LEBIH CEPAT MPLS DARIPADA VPN \\
\hline $16 \mathrm{MB}$ & 21,10 & 0,13 & LEBIH CEPAT MPLS DARIPADA VPN \\
\hline $32 \mathrm{MB}$ & 35,46 & 0,06 & LEBIH CEPAT MPLS DARIPADA VPN \\
\hline $64 \mathrm{MB}$ & 51,62 & 0,06 & LEBIH CEPAT MPLS DARIPADA VPN \\
\hline $128 \mathrm{MB}$ & 66,40 & 0,00 & MPLS DAPAT MENGIRIM FILE \\
\hline $256 \mathrm{MB}$ & 77,89 & 0,00 & MPLS DAPAT MENGIRIM FILE \\
\hline 512 MB & 85,37 & 0,00 & MPLS DAPAT MENGIRIM FILE \\
\hline $\begin{array}{c}\text { RATA } \\
\text { RATA }\end{array}$ & 36,12 & 0,10 & $\begin{array}{c}\text { KECEPATAN } \text { RATA-RATA UNGGUL } \\
\text { MPLS }\end{array}$ \\
\hline
\end{tabular}

Penjelasan pada tabel 5 bahwa hasil analisa perbandingan kecepatan transfer antara jaringan MPLS dengan jaringan VPN membuktikan jaringan MPLS lebih cepat daripada jaringan VPN. Rata-rata kecepatan transfer pada jaringan MPLS sebesar 36,12 Mbps dan pada jaringan VPN sebesar 0,10 Mbps. Jaringan MPLS lebih cepat daripada jaringan VPN karena jaringan yang dirancang dalam VPN melibatkan jaringan internet yang kecepatannya dibawah jaringan lokal yang digunakan dalam perancangan MPLS. Kemudian memperoleh perbedaan kecepatan transfer pada modem yang menghubungkan jaringan VPN STTA. Hal ini membuktikan kecepatan transfer pada modem ketika akan melakukan pengujian berbeda jauh dengan kecepatan transfer yang sebenarnya (dibandingkan dengan perhitungan kecepatan secara manual). Pada uji tes kecepatan transfer modem pada laptop sebelum melakukan pengujian, tercatat bahwa kecepatan upload-nya adalah 1,22 Mbps. Tetapi pada 
kenyataannya, hasil perhitungan kecepatan transfer secara manual pada jaringan VPN STTA bahwa rata-rata kecepatan transfernya hanya memperoleh kecepatan 0,10 Mbps.

\section{Kesimpulan dan Saran}

Dalam pelaksanaan dan pengujian lalu menganalisa hasil pengujian, diperoleh beberapa kesimpulan pada tugas akhir ini. Adapun kesimpulan tersebut antara lain:

1. Rancangan jaringan komputer yang digunakan untuk memindahkan data dalam konfigurasi MPLS dan VPN dengan router Mikrotik berhasil diterapkan.

2. Rancangan aplikasi untuk memindahkan dokumen melalui MPLS dan VPN dapat digunakan dan sudah diuji, aplikasi ini diberi nama ATF (Adisutjipto Transfer Files).

3. Jaringan MPLS lebih cepat dibandingkan jaringan VPN dalam hal kecepatan waktu yang dibutuhkan, dan kecepatan transfer datanya.

Beberapa saran diperoleh dari pelaksanaan tugas akhir ini adalah:

1. Program ATF dapat diganti dengan menggunakan fitur open file atau bisa juga menggeser file untuk memilih file dari explorer ke program dan save file untuk menyimpan file hasil pengiriman.

2. Program ATF dapat dikembangkan pada alat pencarian IP jika yang menjalankan program ATF dapat menampilkan pengguna yang mengaktifkan konfigurasi penerima dan dapat menampilkan IP secara otomatis apabila pengguna menjalankan program ATF.

3. Pengembangan program ATF dapat dilakukan untuk mengirim file dengan kapasitas yang lebih besar lagi.

4. Program ATF dapat dikembangkan tidak hanya untuk mengirim file, tetapi dapat juga untuk melakukan chatting maupun video call dengan sesama pengguna.

\section{Daftar Pustaka}

Bongale, A. M. 2012. Nithin N "Analysis of Link Utilization in MPLS Enabled Network using OPNET IT Guru" : MIT.

Kebria, M. R. 2012. "Analyzing IP/MPLS as Fault Tolerant Network Architecture", Linkoping University : Sweden.

Purbo, Onno W. 1999. "TCP/IP dan Implementasinyd", Jakarta : Elex Media Komputindo.

Rijayana, Irwan. 2005. “Teknologi Multi Protocol Label Switching (Mpls) Untuk Meningkatkan Performa Jaringan", Bandung: Universitas Widyatama.

Stalling, William. 2000. "Data and Computer Communications, 5th Edition", Prentice-Hall Inc. New Jersey.

Syafrizal, Melwin. 2005. "Pengantar Jaringan Komputer", Yogyakarta : ANDI.

Tanenbaum, Andrew S., Wetherall, David J. 2011. "Computer Networks 5th Edition", US: Pearson Education.

Tanenbaum, Andrew S. 2000. "Jaringan Komputer edisi Bahasa Indonesia", Jakarta: Prenhalindo. http:/ / www.gaptek.info/pengertian-modem.html, diakses pada tanggal 28 November 2013. http://www.mikrotik.co.id/produk_lihat.php?id=255, diakses pada tanggal 28 November 2013. 
http:/ / www.wiki.mikrotik.com/index.php?oldid=16990, diakses pada tanggal 28 November 2013.

http:/ / www.routerboard.com/RB750GL, diakses pada tanggal 28 November 2013.

http:/ / www.speedtest.net, diakses pada tanggal 2 Januari 2014. 
Ubrahim Saleh, Hero Wintolo, Dw Nugraheny 